
Attribution licence (http://creativecommons.org/licenses/by/4.o/), which permits unrestricted re-use, distribution, and reproduction in any medium, provided the original work is properly cited.

\title{
The Dialectical Illusion in Kant's Only Possible Argument for the Existence of God
}

\author{
NOAM HOFFER \\ Ben-Gurion University of the Negev \\ Email: noamhoffer@gmail.com
}

\begin{abstract}
The nature of Kant's criticism of his pre-Critical 'possibility proof' for the existence of God, implicit in the account of the Transcendental Ideal in the Critique of Pure Reason, is still under dispute. Two issues are at stake: the error in the proof and diagnosis of the reason for committing it. I offer a new way to connect these issues. In contrast with accounts that locate the motivation for the error in reason's interest in an unconditioned causal ground of all contingent existence, I argue that it lies in reason's interest in another kind of unconditioned ground, collective unity. Unlike the conception of the former, that of the latter directly explains the problematic ontological assumption of the possibility proof, the existence of intelligible objects as the ground of possibility. I argue that such Platonic entities are assumed because they are amenable to the kind of unity prescribed by reason. However, since the interest in collective unity has a legitimate regulative use when applied to the systematic unity of nature, the conception of God entailed by the possibility proof is retained as a regulative idea of reason.
\end{abstract}

Keywords: Kant, Only Possible Argument, ideal of reason, dialectical illusion

\section{Introduction}

In the Critique of Pure Reason, Kant famously argues for the impossibility of proving the existence of God by refuting three arguments, the ontological, the cosmological and the physico-theological. ${ }^{\mathrm{I}} \mathrm{He}$ also criticizes these arguments in the pre-Critical period. ${ }^{2}$ Yet in texts from this period Kant also presented his unique theoretical argument for the existence of God, usually called the possibility proof. This argument is not explicitly discussed in the Critique, but it is mostly accepted that Kant's discussion 
in section two of the chapter 'The Ideal of Pure Reason', titled 'The Transcendental Ideal', involves an implicit criticism of the possibility proof. ${ }^{3}$ Following Grier's influential account of Kant's critique of metaphysics (Grier 200I: 9-10), the reconstruction of Kant's criticism can address two issues: the metaphysical error in the proof itself; and the illusion motivating the metaphysical error, which supposedly stems from a certain interest of reason.

Regarding the metaphysical error, Abaci's recent elaborate and illuminating account identifies it as taking the principle that 'every real possibility must be grounded in actuality' (the actualist principle, AP) (Abaci 20I7: 262) as an 'ontological principle unrestrictedly applying to the real possibility of things in general' (264). This ontological guise of the principle grounds the inference to a necessarily existing being. Regarding the motivation, Abaci locates the source of the error in a way which is mostly continuous with Grier's account of the illusion related to the transcendental ideal $(272-4,279,28 \mathrm{I})$. According to this account, the motivation for taking the conclusion as objective is not presented in the reconstruction of the possibility proof implied in section two, but only in section three of the Ideal chapter, which details a separate illusory inference leading to the necessary ground of all contingently existing things (Grier 200I: 252-6; Grier 20I0: 272-5).

The account I develop in this article is mostly in agreement with Abaci's account of the metaphysical error. But I disagree with Abaci and Grier about the nature of the transcendental illusion that motivates it. Building on Abaci's account, I make the ontological assumption of the possibility proof more specific. When applied as an ontological principle to things in general, AP entails that possibility is grounded in intelligible (abstract) entities from which the proof aims to infer an ultimate groundGod. I argue that this Platonist assumption makes the proof appealing because such an intelligible ground is amenable to the collective unity sought by reason, a conceptual and systematic kind of unity. For the critical Kant, the existence of a unified intelligible ground of the possibility of things transcends the conditions of possible experience and hence is unknowable. Yet the assumption of such a ground is retained as a regulative idea for science because it expresses the interest of reason in the systematic unity of the laws of nature.

In section 2 I briefly present the pre-Critical possibility proof and its transformation into the transcendental ideal of the first Critique. In section 3 I begin to unpack Kant's implicit criticism of the error in the possibility 
proof, the assumption of an ontological ground for the possibility of things in general. In section $4 \mathrm{I}$ show that the implicit criticism also encompasses the motivation of the error, reason's interest in collective unity as the unconditioned ground of all possibility. In section 5 I address the interpretation espoused by Grier, according to which the illusion motivating the error lies in a separate inference to an unconditioned ground for the existence of contingent things. I argue that this can motivate assent to the conclusion, but not the initial assumption of the proof, the ontological AP. I also show that this reading is problematic when considering Kant's pre-Critical refutation of the cosmological argument. To support my alternative explanation, in section 6 I expand on the erroneous ontological commitment of the possibility proof, the assumption of intelligible objects (intelligibilia) as the ground of possibilities. I support this explanation by recourse to the Amphiboly chapter, which clarifies why the transcendental ideal is the paradigmatic example of an intelligible object. In section 7 I provide further evidence for my reading by showing how the positive regulative role of the idea of God stems from the same interest in collective unity which motivates the error of assuming the existence of intelligible objects.

\section{The Transcendental Ideal and the Possibility Proof}

Kant's pre-Critical possibility proof for the existence of God is first presented in 1755 (NE, I: 395) and then elaborated in I763 (OPA, 2: 77-92). The gist of the argument is as follows:

(I) The possibility of any individual thing presupposes not only a logical condition, i.e. the non-contradiction of its predicates, but also a material condition: the content of its predicates is given through some actual thing, either directly from predicates of an actual thing or indirectly derived from fundamental predicates of an actual thing (OPA, 2: 77-8).

(2) Using the notion of a material condition, Kant contends that the possibility of any individual thing is grounded in something actual (following Abaci, principle AP).

(3) If there are no actual things, i.e. nothing exists, no predicates can be given, and therefore nothing is possible.

(4) It is impossible that nothing is possible and therefore

(5) It is necessary that something exists.

(6) There exists one being grounding all possibilities. Since without this being nothing would be possible, this being exists necessarily. ${ }^{4}$

(7) This necessarily existing ground of all possibility is God. 
The argument is problematic in various ways, as pointed out by many commentators. ${ }^{5}$ However, I will forgo here the examination of the various problems because my concern is Kant's own rejection of the proof in the Critique of Pure Reason and the dialectical illusion he associates with it.

I will only make one point about (2) which is relevant for the rest of my argument. There are various interpretations about the nature of the grounding relation between the actual thing and the possible predicates. The debate revolves mainly around the question whether possible predicates are grounded in virtue of being instantiated in something actual or by some other means. ${ }^{6}$ Abaci, for example, maintains that a predicate is made possible in virtue of its 'instantiation' in an existing thing (Abaci 20I 7: 265). It is true that a predicate's being instantiated logically entails that it is possible. Under some accounts, instantiation might also be a condition for the epistemic fact that a predicate is knowable. Indeed, Kant sometimes expresses the grounding relation in epistemic terms, as the requirement for a material element to be given for thought. ${ }^{7}$ But since the argument aims to derive an ontological claim from the grounding of possibility, the grounding relation is not only a logical or epistemological relation but rather a metaphysical one that entails some ontological assumptions about its relata. ${ }^{8}$ Thus, apart from the question of 'instantiation', we need to consider other features of the relata to reveal what is entailed ontologically from the grounding of possibility. The grounded things are predicates of possible things and so are abstract entities, and therefore it is plausible to think also of the ground as an abstract entity. One way to characterize such a metaphysical grounding relation is as a sort of Platonism about the grounds of possibility ${ }^{9}$. I will argue that Kant's realization that proving the existence of God from the grounds of possibility involves the reifications of concepts into abstract entities explains the ultimate rejection of the possibility proof, as well as the regulative significance of the corresponding conception of God.

Kant continued to value this proof in the Critical period. ${ }^{\circ}{ }^{\circ}$ In his lectures on rational theology given after the publication of the Critique, he continues to mention it favourably:

Here [in $O P A]$ it was shown that of all possible proofs, the one which affords us the most satisfaction is the argument that if we remove an original being, we at the same time remove the substratum of the possibility of all things. But even this proof is not apodictically certain; for it cannot establish the objective 
necessity of an original being, but establishes only the subjective necessity of assuming such a being. (LPR, 28: I034)

Although the proof 'affords the most satisfaction', Kant states that it cannot prove the objective existence of God, but only the subjective necessity of assuming it. But what prevents the proof from being apodictically certain? Kant's transcendental idealism entails that knowledge is limited to what can be given in sensible intuition and the a priori conditions of experience. Hence knowledge about a supersensible object such as God is impossible. The natural question that arises is whether, beyond the restrictions of transcendental idealism on knowledge of the conclusion, there is a fallacy within the proof itself. Without locating such a fallacy, the proof could perhaps provide a counter-argument overriding the justifications for transcendental idealism, proving that we can know the existence of at least one object of traditional metaphysics independently from the conditions of possible experience. ${ }^{\text {II }}$

In the Critique itself, Kant does not explicitly mention the possibility proof among the arguments for the existence of God. But a similar line of thought underlies his discussion of the theoretical conception of God as the ens realissimum (the most real being) in section two of 'The Ideal of Pure Reason', 'the transcendental ideal' (A 57 I-84/B579-662). The construal of this conception begins here not from the grounding of possibility, but from the principle of thoroughgoing determination:

Every thing, however, as to its possibility, further stands under the principle of thoroughgoing determination; according to which, among all possible predicates of things, insofar as they are compared with their opposites, one must apply to it. (A57I-2/B599-600)

To put it simply, this principle prescribes what it is like to know everything there is to know about something, so that this knowledge would suffice 'to cognize a thing completely', i.e. as an individual object, solely through its concept $\left(\mathrm{A}_{573} / \mathrm{B} 60 \mathrm{O}\right)$. The principle of contradiction places logical constraints on concepts so that at most only one of a pair of contradicting predicates can apply to each concept of a thing. The principle of thoroughgoing determination, on the other hand, specifies the conditions for the individuation of a thing through its concept, i.e. in terms of a set of predicates: that one of each pair of all possible contradicting predicates applies to the object. According to the principle of the identity of indiscernibles, objects with the same set of predicates are identical, and hence 
the complete set of predicates uniquely identifies an individual object. Thus determining the complete set of predicates presupposes a totality of all possible predicates, 'the entire storehouse of material from which all possible predicates of things can be taken' $\left(\mathrm{A}_{575} / \mathrm{B} 603\right)$. The sum total of all predicates is also the whole of reality (omnitudo realitatis) when considering positive predicates as signifying a reality and negative predicates as lack of reality. Each concept of an individual thing can then be determined by selecting a subset from this whole. Till now, the result is entirely conceptual, without making an ontological claim:

Yet all of this does not signify the objective relation of an actual object to other things, but only that of an idea to concepts, and as to the existence of a being of such preeminent excellence it leaves us in complete ignorance. (A $579 / \mathrm{B} 607$ )

What enables the ontological shift in the final step is regarding the ground of the whole of reality as a single object. The ground of all reality should be thought of as prior to its parts and not as a mere aggregate of parts. Hence there is a shift from the notion of a sum total that can be limited to something that grounds all realities:

[T] he highest reality would ground the possibility of all things as a ground and not as a sum total; and the manifoldness of the former rests not on the limitation of the original being itself, but on its complete consequences, to which our whole sensibility, including all reality in appearance, would then belong, which cannot belong to the idea of a highest being as an ingredient. (A 579/B607)

One reason for this shift is reason's demand for an unconditioned condition. An aggregate of independent parts would be conditioned by their parts and therefore not unconditioned. A second reason appears at the end of the last quote: the ground of all reality is also the ground of sensible realities, and those can only be grounded in the highest being but not included in it without sliding into Spinozism. What is important to note is that this shift brings us closer to the ontological commitment of OPA: the transcendental ideal is not only a concept of an aggregate of predicates but an ontological ground for predicates, which means that they are being regarded ontologically as abstract entities.

When taken as a single object, the ground of all reality is the most real being, the ens realissimum (A $576 / \mathrm{B} 604)$, or in other words, God (A $580 / \mathrm{B} 608)$. 
Since the conceptual individuation of things explains their possibility qua individuals, God as the condition for thoroughgoing determination is also 'the material ground of all possibility' (A573/B60I; cf. A576/B604). The latter is the same term used in the possibility proof. The same 'all of reality' required for thoroughgoing determination of things is also the material ground, the real element of their possibility in the pre-Critical sense. Thus the affinity between this argument and the construal of the ideal of reason in the Critique is evident, textually and conceptually. ${ }^{\mathrm{I} 2}$

\section{The Error of Subreption in the Possibility Proof}

Since the construal of the ens realissimum is similar to the reasoning of the possibility proof, it is plausible to look for criticism of the proof in the analysis following this construal. Kant makes it clear that forming the concept of the ens realissimum does not include an assertion about the existence of its object:

It is self-evident that with this aim - namely, solely that of representing the necessary thoroughgoing determination of things reason does not presuppose the existence of a being conforming to the ideal. (A $577-8 / \mathrm{B} 605-6)$

The conclusion of the possibility proof, however, does assert the actual existence of God, and from similar considerations to the ones leading to the construal of the ens realissimum. Where does this erroneous conclusion come from? After presenting how reason construes the ens realissimum, Kant sets the task to identify the source of the error of inferring its existence, the dialectical illusion:

It is not enough to describe the procedure of our reason and its dialectic; one must also seek to discover its sources, so as to be able to explain this illusion itself ... Therefore I ask: How does reason come to regard all the possibility of things as derived from a single possibility, namely that of the highest reality, and even to presuppose this possibility as contained in a particular original being? $\left(\mathrm{A}_{5} 8 \mathrm{I} / \mathrm{B} 609\right)^{\mathrm{I} 3}$

Kant's account of the nature of the error that leads reason to regard 'all the possibility of things' as grounded in one being is packed into the last two paragraphs of section two and is very succinct and opaque. I will, therefore, analyse it in detail. The account begins with the starting premise of the possibility proof, the grounding of possibility in actuality (AP). 
Kant states that this principle is valid for the possibility of cognizing objects of experience:

The possibility of objects of sense is a relation of these objects to our thought, in which something (namely, the empirical form) can be thought a priori, but what constitutes the material, the reality in appearance (corresponding to sensation) has to be given; without that nothing at all could be thought and hence no possibility could be represented. (A 58 I/B609)

Kant begins by alluding to the Postulates of Empirical Thinking (A2 I 826/B266-74). ${ }^{\mathrm{I}}$ In their legitimate empirical use, the categories of modality do not determine anything in the object itself but only the relation of thought to the object. Two elements can be discerned in this relation. First, the object has to correspond with the formal conditions of experience, the a priori forms of sensible intuition and the categories. Secondly, the content (or matter) of the sensible realities which belong to the object 'has to be given' (A 58 I/B609), i.e. regarded as actual. ${ }^{15}$ Thus the possibility of cognizing empirical objects presupposes the whole of experience as an actual sum-total of all sensible realities:

But because that which constitutes the thing itself (in appearance), namely the real, has to be given, without which it could not be thought at all, but that in which the real in all appearances is given is the one all-encompassing experience, the material for the possibility of all objects of sense has to be presupposed as given in one sum total. ( $\mathrm{A}_{5} 82 / \mathrm{B} 610$ )

This sum total is then conceived as the condition of the thoroughgoing determination of empirical objects: 'all possibility of empirical objects, their difference from one another and their thoroughgoing determination, can rest only on the limitation of this sum total' (A $582 / \mathrm{B} 610$ ). This line of thought is analogous to the starting point of the possibility proof. Also there, Kant distinguishes between the formal aspect of possibility (the principle of non-contradiction), and the material aspect, the actual ground of possibility (AP). But Kant contends that this analogy is deceptive: while AP is true for cognizing the possibility of empirical objects, it is not applicable to grounding the possibility of things in general:

In accordance with a natural illusion, we regard as a principle that must hold of all things in general that which properly holds 
only of those which are given as objects of our senses. Consequently, through the omission of this limitation we will take the empirical principle of our concepts of the possibility of things as appearances to be a transcendental principle of the possibility of things in general. $\left(\mathrm{A}_{5} 82 / \mathrm{B} 6 \mathrm{IO}\right)$

This is a case of 'transcendental subreption', by which a principle of possible experience is illegitimately used to gain knowledge of things independently of possible experience. i.e. things-in-themselves. ${ }^{16}$

As Abaci shows, in its legitimate use for objects of experience, AP is an epistemological principle: for cognizing the possibility of empirical objects as fully determined regarding all realities, we presuppose the actuality of all the empirical realities in one sum total. ${ }^{17}$ The metaphysical error lies in substituting an epistemological AP applicable to the cognition of objects of experience with an ontological AP applied to things in general (Abaci 20I7: 285). But a complete critique of the possibility proof requires not only identifying the metaphysical error but also explaining the transcendental illusion that motivates reason to commit the error. Abaci focuses mainly on the error, and in continuity with Grier claims that the explanation of the illusion comes only in section three of the Ideal chapter. In the next section I lay out my alternative account of the illusion, and in section 5 I argue against Grier's account.

\section{Collective Unity and the Formation of the Transcendental Ideal}

In what follows I will show that there is an implicit account of a motivating illusion already in section two, in the notion of collective unity which comes up in the last paragraph of the section:

That we subsequently hypostatize this idea of the sum total of all reality, however, comes about because we dialectically transform the distributive unity of the use of the understanding in experience, into the collective unity of a whole of experience; and from this whole of appearance we think up an individual thing containing in itself all empirical reality. (A $582 / \mathrm{B} 6 \mathrm{IO}$; italics mine)

The subreption that transforms the epistemological AP into an ontological AP is manifested by hypostatization, i.e. regarding the idea of a ground of possibility as a real object. I take the 'because' in the above sentence to indicate a purposive explanation: the subreption is motivated by an interest in transforming distributive unity into collective unity. 
What is the difference between these kinds of unity? In the Appendix to the Dialectic, Kant describes them as follows:

[J]ust as the understanding unites the manifold into an object through concepts, so reason on its side unites the manifold of concepts through ideas by positing a certain collective unity as the goal of the understanding's actions, which are otherwise concerned only with distributive unity. (A644/B672)

The unity imposed by the understanding on the sensible manifold is distributive, while collective unity is a unity of reason, imposed on concepts (cf. Guyer 2003: 5). According to their seat correspondingly in the understanding or in reason, we can make the following distinction. The distributive unity of the understanding is generated by the relations among objects of experience, the way in which each object is constituted by its relations to all other objects and the cognizing subject. ${ }^{18}$ This unity is therefore distributed equally among its parts. The indeterminate whole composed thereby is only thought as an open series enabling the search for further relations without a definite endpoint. However, as a faculty of inferences, reason demands a different kind of unity, a collective unity of a system derivable from a single ultimate principle:

[W] hat reason quite uniquely prescribes and seeks to bring about concerning it [the concepts of the understanding] is the systematic in cognition, i.e., its interconnection based on one principle. (A645/B673)

Although the paragraph at the end of section two refers to the 'collective unity of a whole of experience' leading to an 'individual thing containing in itself all empirical reality', we should note that this collective unity is not a necessary condition for the possibility of experience but a mere idea of reason. Since collective unity originates in the faculty of reason, it requires something beyond what is available through the synthesizing function of the understanding regarding sensible intuition. ${ }^{19}$

This 'collective unity of a whole of experience' is then 'by means of the transcendental subreption ... confused with the concept of a thing that stands at the summit of the possibility of all things, providing the real conditions for their thoroughgoing determination' (A583/B6II). What motivates this confusion? My claim is that the confusion, the error of subreption, is motivated by the interest of reason in collective unity. As noted above, the unity of experience is merely distributive, the unity resulting 
from the spatial, temporal and categorical relations between the objects of experience. But the interest of reason is to regard any manifold as a collective unity, i.e. a unity in virtue of being derived from a single principle. Since the unity between the actual objects of experience cannot be collective but only distributive, reason presupposes unity in what grounds the possibility of the objects of experience. The ontological ground of possibility is amenable to the unity of reason because it is an abstract entity that can be thought through the reification of concepts. ${ }^{20}$

Thus an important step in the course of reason concluding in the existence of the ens realissimum is the reification of a concept that unites all other concepts systematically as an actual object that grounds all possibility of things. This is suggested in a footnote: 'This ideal of the supremely real being, even though it is a mere representation, is first realized (realisiert), i.e., made into an object (Objekt), then hypostatized' (A $582-3$ / B6IO-II, n.).

The hypostatization (assigning existence) of the ens realissimum is the erroneous conclusion, but there is a prior step mentioned in this sentence, that of 'realization', i.e. thinking it as an object, ${ }^{2 \mathrm{I}}$ or what I called above reification. Once it is conceded that the Ideal designates an object that grounds all possibility, it is natural to infer its necessary existence, as without it nothing would be possible.

Let us summarize Kant's account of the errors that follow from the construal of the ens realissimum:

I. A principle valid for the possibility of cognizing empirical objects is applied to the possibility of things in general for which it cannot be demonstrated to be valid (the dialectical subreption of AP).

2. The unity of experience which is only distributive is transformed into a collective unity of a system of concepts, in accord with an interest of reason.

3. Using this ontological AP, reason infers a single actual object which is the unconditioned ground of the possibility and collective unity of all things in general - God.

What is the relation between (I) the dialectical subreption of AP and (2) the error of substituting collective unity for distributive unity? My claim is that there is a rational interest regarding the unifying distributive relations between empirical objects as grounded by the collective unity of relations between concepts. Thus reason is tempted to take its interest in 
(2) as objective, justifying the ontological commitment entailed by the subreption (I). Regarding the collective unity of reason as objective means making concepts into objects: making something which signifies only the relation 'of an idea to concepts' into an 'objective relation of an actual object to other things' (A 579/B607). This leads to a metaphysical error when the objects thereby produced, purely intelligible objects, are regarded as existing. In section 6 I will expand on the nature of these objects and show how they function in the construal of the ens realissimum and the possibility proof.

The following note provides additional evidence that it is this interest in collective unity which ultimately motivates the formation of the ens realissimum:

The idea of the unconditioned unity of all objects of thought in an ens entium is necessary in order to seek for the affinity among everything possible and thereby also thoroughgoing connection as unity of principle. ( $\mathrm{R}_{5553}$, I 8: 226; the three emphases mine; cf. the footnote to $\mathrm{A}_{572} / \mathrm{B} 600$ )

The ens realissimum is construed for the sake of an unconditioned ground of the unity among all possibilities, i.e. unity among the essences which provide the 'matter' for all possible things. Hence the metaphysical error arises from thinking that the unity of concepts prescribed by reason has to be grounded in actual intelligible objects: 'where the universality of thinking through reason is taken for a thought of a totality of the possibilities of things' (R5553, I 8: 224). In section 7, I show how this kind of unity receives a regulative status.

\section{Transcendental Illusion and Section Three of the Ideal}

According to Grier, the construal of the ens realissimum in section two of the Ideal chapter does not include an explanation of the illusion motivating the error, which comes only in section three. Thus she claims 'that section 2 and 3 constitute two stages in a single extended argument'. ${ }^{22}$ The following passage at the beginning of section three supports this reading:

In spite of its urgent need to presuppose something that the understanding could take as the complete ground for the thoroughgoing determination of its concepts, reason notices the ideal and merely fictive character of such a presupposition much too easily to allow itself to be persuaded by this alone straightway to assume a mere creature of its own thinking to 
be an actual being were it not urged from another source to seek somewhere for a resting place in the regress from the conditioned, which is given, to the unconditioned. $\left(\mathrm{A}_{5} 83-4 / \mathrm{B} 6 \mathrm{I} \mathrm{I}-\mathrm{I} 2\right)$

Kant claims that the need to assume the material ground for thoroughgoing determination presented in section two is not persuasive enough to form belief in the actual existence of God without another motivation. This other motivation for belief in the existence of God is the argument that begins with contingent existence known through experience and concludes that there is something that exists necessarily, a cause for the whole series of contingent things:

If something, no matter what, exists, then it must also be conceded that something exists necessarily. For the contingent exists only under the condition of something else as its cause, and from this the same inference holds further all the way to a cause not existing contingently and therefore necessarily without condition. That is the argument on which reason grounds its progress to the original being. (A $\left.584 / \mathrm{B} 6 \mathrm{I}_{2}\right)$

The existence of each contingent thing is caused by something else. The general interest of reason is to complete the regress of causal conditions, and therefore it postulates an unconditioned cause for the whole series. This type of inference corresponds to the generic form of a transcendental illusion that Grier identifies in all the arguments of the dialectic: a transition from the legitimate yet subjective principle of reason, 'Find for the conditioned knowledge given through the understanding the unconditioned' $(\mathrm{PI})$, to the illusory principle, 'If the conditioned is given, the whole series of conditions, subordinated to one another - a series which is therefore itself unconditioned - is likewise given' $\left(\mathrm{P}_{2}\right){ }^{23} \mathrm{P}_{2}$ is here applied to the causal series of contingent things, resulting in a necessary first cause. Kant then continues to assert that only the unjustified combination of the two lines of thought, the first from the principle of thoroughgoing determination to the ens realissimum, and the second from the series of contingent things to their non-contingent cause, leads to the illusion of rational theology in its full force. Reason is compelled to assume the unconditioned cause for contingent things but has no insight into its nature. The concept of the most real being is then introduced as 'best suited to the concept of an unconditionally necessary being' (A 587 ) B6I 5). The ens realissimum is best suited for a concept of an unconditioned cause because it is unconditioned also in another sense, as the most real being which grounds the possibility of everything else. 
According to Grier, it is only the need for an unconditioned causal ground of existence added in section three that accounts for the dialectical illusion motivating the hypostatization of the ens realissimum. ${ }^{24}$ Yet her account does not explain the relations between the series of errors detailed in section two, but only the appeal of using its final conclusion for a different purpose. $^{25}$ Therefore, when considering the account of these errors as an implicit criticism of the possibility proof, locating the motivating illusion only in section three cannot explain how the pre-Critical Kant thought the possibility proof was convincing in the first place.

Moreover, the argument presented in section three for a necessarily existing cause of all contingent things is a version of a cosmological argument for the existence of God. Given that the construal of the ens realissimum in section two correlates with the pre-Critical possibility proof, locating the illusion only in section three would amount to the claim that the force of the possibility proof depends on an implicit appeal to the cosmological argument for supplying the concept of necessary existence. But could Kant be committed to this position? In OPA he explicitly maintained the opposite view: the possibility proof is the 'only possible argument' and superior to all other arguments, including the cosmological argument from contingency.

The specific criticism of the cosmological argument in OPA (2: I 58$)$ is similar to the one levelled in the Critique (A604-7/B632-5), and shows that it implicitly depends on the Cartesian ontological argument. What is relevant for the present purpose is Kant's claim that the possibility proof is superior to the cosmological proof precisely with respect to the notion of necessary existence. The possibility proof renders the necessary existence of God intelligible because it proceeds from an analysis of the concept of absolute necessity as that whose non-existence cancels all possibility, while the cosmological proof appeals to the merely negative notion of the non-contingent:

It [the possibility proof] is, indeed, an argument derived from the internal characteristic mark of absolute necessity. Thus, our knowledge of the existence of this being is derived from what really constitutes the absolute necessity of that same being ...

None of the proofs which argue from the effects of this being to its existence as cause can ever - even granting that they are of the strictest character, which in fact they are not - render the nature of this necessity comprehensible ... from the fact that something 
is a first cause, that is to say, an independent cause, it only follows that, if the effects exist then the cause must also exist, not that the cause exists absolutely necessarily. (OPA, 2: 9I; emphases mine)

I believe that it is unlikely that Kant changed his mind about the independence of the possibility proof from the cosmological proof. If this is the case, then there should be another kind of motivating illusion than the one Grier locates in section three, which explains why the mere conception of the transcendental ideal is mistaken for a proof from the ground of possibility. As I have shown in the previous section, this illusion stems from the interest in the collective unity of all possibilities. We should note that the collective unity of the grounds of possibility is also a form of an unconditioned ground, and hence stemming from the general illusory principle $\mathrm{P}_{2}$, but it is not the unconditioned ground of existence described in section three.

But how are we to understand Kant's statement about the lack of convincing power of the procedure in section two which correlates with the possibility proof? I suggest we take it as a historical-anthropological observation rather than logical. The cosmological argument is more common in human history because it begins with ordinary experience and does not assume sophisticated metaphysical reflections:

This is the natural course taken by every human reason, even the most common .... It begins not with concepts, but with common experience, and thus grounds itself on something existing. (A $\left.584 / \mathrm{B} 6 \mathrm{I}_{2}\right)$

[The argument is] so simple and natural that it is suited to the commonest human understanding as soon as the latter is once led to it. $\left(\mathrm{A}_{5} 89 / \mathrm{B} 6 \mathrm{I}_{7}\right)$

Once human reason is led from the causal series of changes to the idea of a first cause, then further philosophical reflection can supply the idea of a most perfect being as a suitable candidate for that cause. But the logical course of reasoning as exemplified in OPA and still supported in the lectures as subjectively valid does not depend on the cosmological argument and is also not motivated by it, but by another demand of reason, that of collective unity. The next sections will elaborate on the ontological commitment to intelligibilia motivated by this interest and its relation to the regulative principle of systematic unity. 


\section{Intelligibilia and the Ontological Commitment of the Ideal}

The error of subreption is that of taking the 'empirical principle of our concepts of the possibility of things as appearances to be a transcendental principle of the possibility of things in general' $\left(\mathrm{A}_{5} 82 / \mathrm{B} 660\right)$. What is meant by things in general? In several other places, the term 'things in general' is followed by 'and in themselves' (B298/A238, B4IO). Things in general are thought not in relation to the conditions of experience but only as they are in themselves. Leaving out all sensible conditions, any thinkable determination of them would thus be purely intellectual, and the objects would be intelligible objects. We may call these intelligible things in themselves intelligibilia. ${ }^{26}$

We can find the assumption of intelligibilia as related to the idea of God in the introduction to the Dialectic:

[I]n the third kind of sophistical inference, from the totality of conditions for thinking objects in general ... I infer the absolute synthetic unity of all conditions for the possibility of things in general; i.e., from things with which I am not acquainted as to their merely transcendental concept, I infer a being of all beings, with which I am even less acquainted through its transcendental concept, and of whose unconditioned necessity I can make for myself no concept at all. This dialectical syllogism I will call the ideal of pure reason. ( $\mathrm{A}_{340 / \mathrm{B}_{39}}$; emphases mine)

The ens realissimum is not construed through direct reference to objects of experience, in contrast with the cosmological idea which is construed from the totality of appearances. Rather, it is inferred from the "conditions for the possibility of things in general', hence things-in-themselves with which we are not acquainted. Although nothing can be known about such things, reason assumes their existence as purely intelligible when inferring the existence of God.

To get a clearer view of the characteristics of these objects, we should note that the ens realissimum is not only the ground of thoroughgoing determination and the possibility of everything else, it is also described as the prototype, the perfect example, of things in general: 'the ideal is thus the original image (prototypon) of all things, which all together, as defective copies (ectypa), take from it the matter for their possibility' (A $578 / \mathrm{B} 606$ )

The Platonic overtones in the above passage are not accidental. At the outset of the Dialectic Kant explicitly borrows the term 'idea' (Idee) from 
Plato to designate concepts of objects that cannot be given in experience but serve as standards of perfection ( $\left.\mathrm{A}_{32} \mathrm{O} / \mathrm{B}_{377}\right)$. Most of Kant's examples for the significance of Platonic ideas come from the practical realm. But the Ideal chapter shows how theoretical considerations also lead reason to form an ontology of degrees of reality so that the ens realissimum grounds the possibility of all its less perfect copies. By conceiving the possibility of things in general as intelligibilia, reason reifies concepts as objects and makes them dependent on the most perfect object which corresponds with the most complete concept. This is, in other words, Platonism.

This Platonic picture entails that, by discerning the features of the prototype, i.e. the ens realissimum, we can learn what is assumed about the copies, i.e. the objects which depend on it. Because the ground of thoroughgoing determination is also the ground of possibility, this also clarifies the ontological commitments of the possibility proof.

The ens realissimum is a paradigmatic example of a thing-in-itself because by having all perfections and no negations it is individuated solely by conceptual means:

Through this possession of all reality, however, there is also represented the concept of a thing in itself which is thoroughly determined $\ldots$ an individual being, because of all possible opposed predicates, one, namely that which belongs absolutely to being, is encountered in its determination. (A $576 / \mathrm{B}_{604}$; italics mine)

The Amphiboly chapter provides further details about the characteristics of things-in-themselves as intelligibilia. The target of criticism in this chapter is the Leibnizian theory of monads, and the basic thought is that this theory could be justified according to the concepts of reflection if we had cognition of intelligibilia. Yet we do not possess such cognition and the principles valid for intelligibilia are not valid for objects of sensible intuition. What is important for the present purpose is that we can also learn from this discussion what intelligibilia would be like had they existed, and why they are presupposed in the construal of the ens realissimum.

The first pair of concepts of reflection states the identity of indiscernibles $\left(\mathrm{A}_{2} 63-4 / \mathrm{B}_{3}\right.$ I9-20). As noted in section 2, the principle of thoroughgoing determination as a principle of individuation depends on this principle, 
and the ens realissimum itself as a concept of an individual exemplifies it. Thus the principle of thoroughgoing determination from which the construal of the ens realissimum begins is fully applicable only to intelligibilia. Also according to the second and the third pair of concepts of reflection, the ens realissimum is a paradigmatic example of an intelligible thing in itself: there is no opposition between its realities, and all its determinations are intrinsic rather than relational (A264-6/B320-2).

The Amphiboly chapter does not discuss concepts of modality, but the last pair of concepts of reflection, matter and form, is directly related to the grounding of possibility:

In every judgment one can call the given concepts logical matter (for judgment), their relation (by means of the copula) the form of the judgment. In every being its components (essentialia) are the matter; the way in which they are connected in a thing, the essential form. Also, in respect to things in general, unbounded reality is regarded as the matter of all possibility, but its limitation (negation) as that form through which one thing is distinguished from another. ... The understanding, namely, demands first that something be given (at least in the concept) in order to be able to determine it in a certain way. Hence in the concept of pure understanding matter precedes form. (A266-7/B322-3; emphases mine)

Appearances are first individuated by the spatiotemporal form, and only then determined with regard to their content: 'the form of intuition (as a subjective constitution of sensibility) precedes all matter (the sensations), thus space and time precede all appearances and all data of appearances, and instead first make the latter possible' (A267/B 323 ). But regarding intelligibilia, if there were such things, the existence of the matter of their reality could be inferred from their real possibility. The affinity of this discussion of matter and form in the Amphiboly to the construal of the ens realissimum and the possibility proof is clear. The reasoning to the matter of all possibility is conditionally valid for intelligibilia: if one could cognize the existence of such objects, then one could also cognize a sum total of all intelligible reality grounding their possibility.

We should also notice in the above passage that components of intelligible objects are modelled after concepts (the predicates being related 
in judgement) and are called essentialia, the material to be combined in the essential form of a thing. When considering intelligibilia, the matter of all possibility is the totality of essences. Thus the conclusion of the possibility proof that the matter of all possibility is grounded in God is equivalent to the grounding of all essences in God. This notion of a unified ground of essences is exactly what Kant found valuable in the conception of God entailed by the possibility proof and allows its transformation into a regulative idea, as I will suggest in the next section.

To conclude: since the ens realissimum as the paradigmatic concept of an intelligible thing-in-itself is inferred from being the archetype ('the original image') grounding the possibility of all other things, those things, i.e. intelligibilia, are assumed to exist.

\section{The Regulative Use of the Ideal}

In the series of the metaphysical errors following the formation of the ens realissimum, it is not only realized and hypostasized as an existing object but also made into a thinking substance:

This ideal of the supremely real being, even though it is a mere representation, is first realized, i.e., made into an object, then hypostatized, and finally, as we will presently allege, through a natural progress of reason in the completion of unity, it is even personified; for the regulative unity of experience rests not on appearances themselves (of sensibility alone), but on the connection of its manifold by understanding (in one apperception); hence the unity of the highest reality and the thoroughgoing determinability (possibility) of all things seems to lie in a highest understanding, hence in an intelligence. $\left(\mathrm{A}_{5} 83 / \mathrm{B} 6 \mathrm{II}, \mathrm{n}\right.$.; italics mine)

As argued above, this whole series of errors is motivated by an interest in collective unity. Since this is a conceptual rather than sensible unity, it is plausible to regard its ground as intelligent. But what is important for the present purpose is that this unity is described as regulative, hinting at the positive regulative role of the ens realissimum.

The regulative use of the ideas of reason is the subject of the Appendix to the Dialectic. The idea of God is specifically related to the systematic unity of nature: 'the idea of that being [God], means nothing more than that reason bids us consider every connection in the world according to principles of a systematic unity' (A686/B7/44). 
In contrast with the legitimate regulative use, the possibility proof not only 'bids us consider', but concludes that there exists an object grounding the systematic unity of all possible things. But leaving aside the objective status of the conclusion, it is important to note that in the pre-Critical possibility proof the conception of God is also related to the systematic unity of nature.

The second part of OPA (2: 93-I 55) discusses at length the systematic order of nature. Kant there criticizes explanations of natural facts that appeal to contingent divine intervention instead of necessary laws of nature. But investigating the latter is not in contrast with including God in the metaphysical explanation of nature. The ground of all possibility is the ground of essences, i.e. the necessary properties of things and the lawful relations between them (cf. Insole $20 \mathrm{II}$ ). Hence investigating the unity of the laws of nature stemming from the essences of things coheres with the conception of God as the single ground of all possibility established in the first part of OPA:

Our purpose from now on will be to see whether the internal possibility of things is itself necessarily related to order and harmony ... so that, on this basis, we could establish whether the essences of things themselves indicate an ultimate common ground. (2:92)

Kant espoused this view about God as the ground of essences and the laws of nature at least from the I 750 os in his drafts on optimism (R 3704 , I7: 234) and the Universal Natural History (I: 222-3, 332), and he continued to hold it in LPR (28: 1035).

The usefulness of this conception of God is transformed in the Critique into a regulative idea expressing the need to assume the unity of the laws of nature. ${ }^{27}$ But taking this need as objective rather than subjective leads to the dogmatic assumption of the possibility proof, that essences exist as intelligible things in themselves from which it is possible to infer their ultimate ground, God.

In LPR Kant contends that the possibility proof establishes 'the subjective necessity of assuming such a being' for explaining 'what in general the possibility of something consists in' (LPR, 28: I034). A note from the I770s provides further elaboration of this subjective necessity:

Even if the existence of God does not follow from the conditions on which we ground the concept of possibility, it nevertheless 
follows sufficiently from the concession that we can judge a priori about this. The subjective conditions of thinking therefore serve very well for convincing cat anthropon, but not apodictically. (R 5508, I 8: 203; emphasis added)

The possibility proof is invalid without the assumption of a priori knowledge about the conditions of possibility in general. Since it proceeds from the ontological ground of possibility in general and not from the epistemic condition for cognizing the possibility of empirical objects, such $a$ priori knowledge would amount to cognition of the matter of possibility as intelligible, hence knowledge about the existence of intelligibilia. ${ }^{28}$ Assuming this kind of knowledge is, in fact, assuming that the structure of thought is also the structure of reality, ${ }^{29}$ and therefore the argument is subjectively valid for human thought, cat anthropon (ad hominem). While this subjective validity is the illusion motivating the unjustified assumptions of the possibility proof, it also correlates with its positive regulative use. Thus although there can be no cognition of essences qua intelligibilia, the idea of God construed as their ground expresses the rational interest in discovering the unity of the laws of nature.

\section{Conclusion}

I have shown that the conception of God as the ens realissimum and the ground of all possibilities is construed from the assumption of intelligible objects. For the pre-Critical Kant, the starting assumption that there are entities such as essences that ground the possibility of empirical objects was unproblematic. From these intelligible entities it was also unproblematic to construct a conception of God. For the Critical Kant, cognition of essences as things-in-themselves is impossible for human cognition. Therefore assuming that these intelligible building blocks of the possibility proof exist objectively is the erroneous result of a dialectical subreption, the application of a principle whose validity cannot be demonstrated for things in general. I have argued that this metaphysical error is not motivated by the interest of reason to seek the unconditioned ground of contingent existence, but by an interest in a different kind of unconditioned, that of conceptual collective unity. It is this interest that also explains the regulative role of the idea of God. Even though the intelligible grounds of possibility are not objects of knowledge, their amenability, as purely intelligible, to collective unity correlates with what guides scientific inquiry, the systematicity of empirical concepts. For this reason, even when losing its objective validity, the conception of God retains a subjective validity as the Ideal of reason, 'a concept which brings to a close and crowns the whole of human cognition' (LPR, 28: I037)..$^{\circ}$ 


\section{Notes}

I I cite Kant from the Akademie edition by reference to volume and page number. Quotations from Critique of Pure Reason are cited by the standard (A/B) pagination. I mostly use the translations of the Cambridge edition of Kant's works (Kant I998, 2000, $200 \mathrm{I}$ [LPR], 2003 [NE, OPA], 2005 [Reflexionen]); if there has been no translation in that edition, translations are mine. References to Kant's unpublished Reflexionen will be given with the numbers of the individual reflections $(\mathrm{R} \#)$, provided in volumes I7, I 8 and I 9 of the Akademie edition. I use the following abbreviations: LPR $=$ Lectures on the Philosophical Doctrine of Religion; NE=A New Elucidation of the First Principles of Metaphysical Cognition; OPA= The Only Possible Argument in Support of a Demonstration of the Existence of God.

2 Kant criticized the Cartesian ontological argument first in NE, I: $394-5$ and then in greater detail together with the two other proofs in OPA, 2: 72-5, I 55-62.

3 However, the exact nature of this criticism varies among interpreters. See e.g. Wood I978: 7I-9; Fisher and Watkins I998; Logan 2007: 357-6I; Rukgaber 20I4: 98-I02; Stang 2016: 288-96; Abaci 2017.

4 This is the most controversial step in most reconstructions of the proof. See e.g. Fisher and Watkins I998: 375; Adams 2000: 432-4; Stang 20I0: 292-4; Boehm 20I4: 27.

5 In addition to the previous note, see also Wood I978: 70-I.

6 See also Adams 2000: 427; Stang 20I0: 280-I; Chignell 20I2: 645-8; Yong 20I4: 38-44; Stang 2016: 107-19; Hoffer 2016: 193-8.

7 E.g.: 'The material element which is given here as standing in such a conflict is itself something and can be thought' (OPA, 2: 77).

8 For a detailed discussion of the ontological commitments of the possibility proof see Kanterian 2017: 209-IO.

9 Independently of Kant's argument, Platonism might be an attractive theory for grounding modal facts. See Berman 20I3.

Io Paul Franks argues that there is a shift in Kant's thought from a dismissive attitude in the first Critique to a more positive attitude in the 1786 Orientation essay (Franks 2005: 66). My explanation of the regulative value of the proof implied in the former supports the view that there is no substantive shift.

II See Fisher and Watkins I998: 380-4. Logan argues that this is indeed the case, that Kant's rejection of his own proof is based on an unjustified empiricist shift in Kant's thought in the late 1760 s (Logan 2007: 354-60). While this might explain the historical development that led to rejection of the proof, I will show in the next section that the Critical Kant refutes the proof by rejecting its main premise and not only its conclusion, and that he also explains the motivation for this premise by appeal to the interests of reason.

I2 Rukgaber 20I4 argues that, although 'the metaphysical vision of the pre-Critical Kant is informing his theory of the transcendental ideal', the argument of section two 'shares nothing with the pre-Critical argument except the idea of the ens realissimum' (Rukgaber 20I4: IOO). I disagree, as the principle of thoroughgoing determination leads to the material substrate required for the possibility of things qua individuals. In this I agree with Stang 20I6: 292.

I3 I have emended the translation by Wood and Guyer which I believe is inaccurate: 'and even to presuppose these possibilities as contained in a particular original being'. The original reads: und diese sodann, als in einem besonderen Urwesen enthalten vorauszusetzen. It is more probable that diese refers to the possibility of the highest being and not to all the possibility of things, both for grammatical reasons, and because it was stated before that God is the ground and not the sum total of all possibilities, hence the latter are 
not contained in God. I thank an anonymous referee for noting this peculiarity in the translation.

I4 This is noted in Wood I978: 64-6; Grier 200I: 240-I; Longuenesse 2005: 219-22; Abaci 20I7: 280-2.

I5 It should be noted that this does not violate the claim that the modal categories do not determine anything in the object; here the presupposed actuality of the sum total of realities is not a judgement that an object is actual but only put forth as a presupposition for the possibility of thoroughgoing determination.

I6 The term is first introduced in the Inaugural Dissertation of $\mathrm{I} 770$ as the 'the confusion of what belongs to the understanding with what is sensitive'. In the Critique, the term is generalized for all cases in which a principle of empirical cognition is extended beyond its boundaries, e.g. inferring the existence of the soul from the unity of consciousness (A389, 402). See also Grier 200I: 246-7; Abaci 2017: 28 5-6.

I7 Note that this sum total is also an idea that cannot be given in experience, and hence empirical cognition can only strive for complete determination but never achieve it. See Abaci 2017: 283-4.

I8 E.g. spatial, temporal and categorical relations: 'everything in our cognition that belongs to intuition ... contains nothing but mere relations, of places in one intuition (extension), alteration of places (motion), and laws in accordance with which this alteration is determined (moving forces)' (B66; cf. A265/B32I).

I9 Longuenesse ignores the distinction between the two kinds of unity and the regulative role of the collective unity. She thus suggests that in these passages Kant offers a critical notion of thoroughgoing determination which can be formulated using the resources of the Analytic alone (Longuenesse 2005: 22 I-2). For criticisms of this reading see Grier 200I: 237-46; Verburgt 20II: 245-52. Fisher and Watkins (I998: 392-5) also argue that the rejection of the possibility proof is based on the distinction between understanding and reason and their different domains, but they do not explain in detail the illusion related to it.

20 In a different context, Glezer (20I7: I64-8) suggests a similar connection between conceptual systematicity and noumenal reality. His ultimate position is incompatible with mine, but a full response is beyond the scope of this article.

2I The German term is Objekt and it is clear that in this context it is not an object of sensible intuition but rather an object in general, thought as a thing in itself.

22 Grier 200I: 233. Abaci (20I7: 287-9) agrees with Grier on this issue.

23 Grier 200I: I2O, I22. As Boehm (20I4: 5I-2) has shown, $\mathrm{PI}_{\mathrm{I}}$ and $\mathrm{P} 2$ can be regarded respectively as subjective and objective formulations of the principle of sufficient reason. This fits well with my reading as it emphasizes that the principle of reason is not only applicable to grounding a causal series of contingent things but to any kind of unconditioned ground.

24 Stang (2016: 293-5) has a different explanation of the illusion, motivating the Ideal in terms of principles which correspond with Grier's $\mathrm{P}_{\mathrm{I}} / \mathrm{P}_{2}$ distinction: a Logical and a Pure Principle of Reason. The illusion stems from applying the latter to the grounds of noumenal real possibility, so that reason supposes that there is a determinate complete set of all possible predicates. Discussing this account is beyond the scope of this article, but I find it compatible with mine: noumenal real possibility is itself a problematic concept of reason since we can only think about its ground as intelligibilia.

25 Willaschek (20I 8: 23 I, n. 22) makes the stronger claim that section two does not discuss the metaphysical error of assuming the existence of the ens realissimum at all, and that this assertion comes only in section three. 
26 'Leibniz took the appearances for things in themselves, thus for intelligibilia, i.e. objects of the pure understanding' ( $\left.\mathrm{A}_{2} 64 / \mathrm{B}_{3} 20\right)$. 'If, however, I suppose there to be things that are merely objects of the understanding ... then such things would be called noumena (intelligibilia)' (A249). See also Allais 2015: 7.

27 More in Hoffer 2019.

28 Although OPA uses examples of empirical objects, the ground of the possibility of their fundamental predicates are essences, hence abstract objects.

29 Willaschek (2018:9) argues that 'the claim that the structure of reality corresponds to that of rational thought' is the erroneous tacit assumption Kant identifies in speculative metaphysics in general).

30 I would like to thank Allen Wood and two anonymous referees for Kantian Review for invaluable comments on earlier drafts of this article. I am also grateful to Nick Stang and other participants of the 2016 North American Kant Society Midwest study group meeting in which an earlier version was presented. This research was supported by the Israel Science Foundation (grants of Ohad Nachtomy, Hagit Benbaji and Ido Geiger).

\section{References}

Abaci, Uygar (20I7) 'Kant, the Actualist Principle, and he Fate of the Only Possible Proof'. Journal of the History of Philosophy, 55(2), 26I-9I.

Adams, Robert Merrihew (2000) 'God, Possibility, and Kant'. Faith and Philosophy, I7(4), $425-40$.

Allais, Lucy (2015) Manifest Reality: Kant's Idealism and his Realism. Oxford: Oxford University Press.

Berman, Scott (2013) 'A Platonic Theory of Truthmaking'. Metaphysica, I4(I), I09-25.

Boehm, Omri (20I4) Kant's Critique of Spinoza. Oxford: Oxford University Press.

Chignell, Andrew (2012) 'Kant, Real Possibility, and the Threat of Spinoza'. Mind, I 2 I $(483), 635-75$.

Fisher, Mark, and Eric Watkins (1998) 'Kant on the Material Ground of Possibility: From "The Only Possible Argument" to the "Critique of Pure Reason"'. Review of Metaphysics, 52(2), 369-95.

Franks, P. W. (2005) All or Nothing: Systematicity, Transcendental Arguments, and Skepticism in German Idealism. Cambridge, MA: Harvard University Press.

Glezer, Tal (20I7) Kant on Reality, Cause, and Force: From the Early Modern Tradition to the Critical Philosophy. Cambridge: Cambridge University Press.

Grier, Michelle (200I) Kant's Doctrine of Transcendental Illusion. Cambridge: Cambridge University Press.

- (2010) 'The Ideal of Pure Reason'. In Paul Guyer (ed.), The Cambridge Companion to Kant's Critique of Pure Reason (Cambridge: Cambridge University Press), 266-89.

Guyer, Paul (2003) 'Kant's Principles of Reflecting Judgment'. In Paul Guyer (ed.), Kant's Critique of the Power of Judgment: Critical Essays (Lanham, MD: Rowman \& Littlefield), I-6I.

Hoffer, Noam (2016) 'The Relation between God and the World in the Pre-Critical Kant: Was Kant a Spinozist?'. Kantian Review, 2I(2), I 8 5-2 IO.

- (2019) 'Kant's Regulative Metaphysics of God and the Systematic Lawfulness of Nature'. Southern Journal of Philosophy, 57(2), 2 I7-39.

Insole, Christopher (20II) 'Intellectualism, Relational Properties and the Divine Mind in Kant's Pre-Critical Philosophy'. Kantian Review, I6(3), 399-427.

Kant, Immanuel (I998) Critique of Pure Reason. Trans. and ed. Paul Guyer and Allen W. Wood. Cambridge: Cambridge University Press. 
(200I) Religion and Rational Theology. Trans. and ed. Allen W. Wood and George di Giovanni. Cambridge: Cambridge University Press.

— (2003) Theoretical Philosophy, 1755-1770. Trans. and ed. David Walford and Ralf Meerbote. Cambridge: Cambridge University Press.

- $(2005)$ Notes and Fragments. Ed. Paul Guyer, trans. Paul Guyer, Curtis Bowman and Frederick Rauscher. Cambridge: Cambridge University Press.

Kanterian, Edward (2017) Kant, God and Metaphysics: The Secret Thorn. New York: Routledge.

Logan, Ian (2007) 'Whatever Happened to Kant's Ontological Argument?'. Philosophy and Phenomenological Research, 74(2), 346-63.

Longuenesse, Béatrice (2005) Kant on the Human Standpoint. Cambridge: Cambridge University Press.

Rukgaber, Matthew (2014) 'Kant's Criticisms of Ontological and Onto-theological Arguments for the Existence of God'. Kant Yearbook, 6(I), 87-II4.

Stang, Nicholas F. (20I0) 'Kant's Possibility Proof'. History of Philosophy Quarterly, 27(3), $275-99$.

- (20I6) Kant's Modal Metaphysics. Oxford: Oxford University Press.

Verburgt, Jacco (20II) 'How to Account for Reason's Interest in an Ultimate Prototype: A Note on Kant's Doctrine of the Transcendental Ideal'. In Dennis Schulting and Jacco Verburgt (eds), Kant's Idealism: New Interpretations of a Controversial Doctrine (Dordrecht: Springer), 237-54.

Willaschek, Marcus (20I8) Kant on the Sources of Metaphysics: The Dialectic of Pure Reason. Cambridge: Cambridge University Press.

Wood, Allen W. (1978) Kant's Rational Theology. Ithaca, NY: Cornell University Press.

Yong, Peter (20I4) 'God, Totality and Possibility in Kant's Only Possible Argument'. Kantian Review, I9(I), 27-5I. 